Document downloaded from:

http://hdl.handle.net/10251/100585

This paper must be cited as:

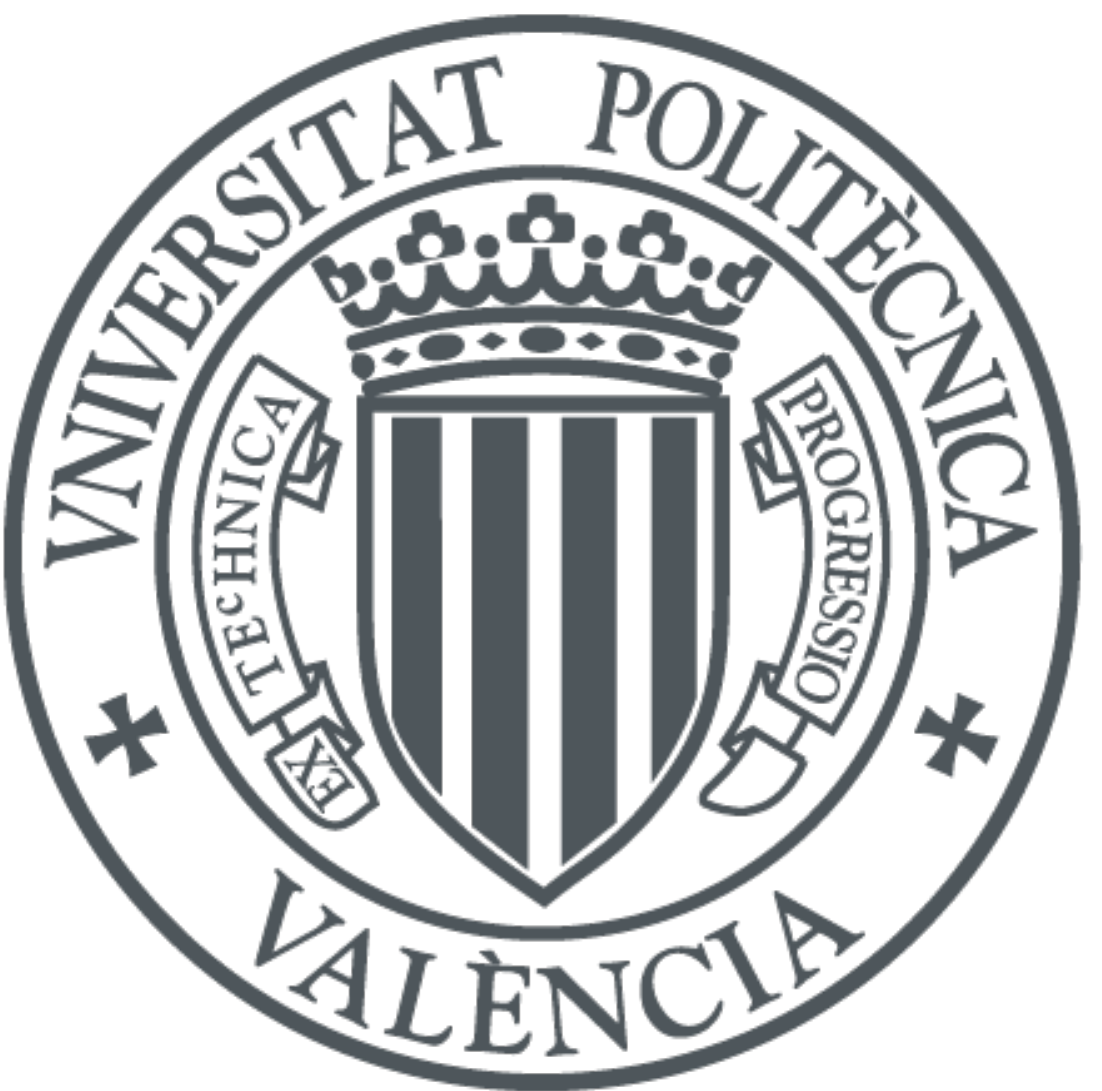

The final publication is available at

https://doi.org/10.1016/j.enbuild.2014.05.006

Copyright Elsevier

Additional Information 


\title{
THERMAL BEHAVIOR ANALYSYS OF DIFFERENT MULTILAYER FAÇADE: NUMERICAL MODEL VERSUS EXPERIMENTAL PROTOTYPE
}

\author{
Ignacio Guillén ${ }^{1}$, Vicente Gómez-Lozano ${ }^{1}$, José María Fran², P. Amparo López-Jiménez ${ }^{3}$ \\ 1. Applied Physics Department. Universitat Politècnica de València. \\ 2. Dept. of Architectural Constructions. Universitat Politècnica de València. \\ 1. Hydraulic and Environmental Engineering Department. Universitat Politècnica de València.
}

Corresponding author: Ignacio Guillén. iguillen@fis.upv.es; tel +34963877522; Fax +34963879525

\begin{abstract}
In this paper, different sort of façades have been analyzed considering their thermal behavior along a 24 hours period. A numerical model has been developed and compared with experimental measurements considering two different façades for buildings: on the one side an opaque multilayer façade; and on the other side, a ventilated façade. The numerical model representing the temperature in every layer of the façades has been successfully validated. This model has been used for determining the thermal behavior of two new ventilated façades in which the thermal mass has been changed, observing then than the existence of the moving in the air gap affects particularly the air temperature and the thermal transmittance of the façade when the sun is incising over the façade, leading to a decrease of transmittance close to $30 \%$ along the air chamber. This quantification is fundamental in warm climates, where this effect is determinant for decreasing the cooling necessities of buildings in summer with no need of increasing the mass of the façade.
\end{abstract}

\section{Keywords}

Thermal analysis, numerical model, ventilated façade, thermal transmittance.

\section{INTRODUCTION}

Nowadays, the analysis of the thermal behavior in a building is of paramount importance, as designers intend to make the heat transmission across walls as low as possible. Besides, the actual technology, so-called passive construction, aims to achieve the best climate conditioning inside buildings. This must be done with the lowest possible energy expenditure by acting on the levels of solar gain, thermal insulation and thermal inertia [1].

The consideration of how the thermal inertia influences in the different façades is determinant to properly analyze the effect of the building envelope in each different climatic conditions. ([2], [3]). Nevertheless, in the common architectural practices, many simplifications are used in order to quantify the façade effect in heat transfer.

This work focuses on the analysis of the thermal behavior of two different facades: conventional façade and ventilated façade. The aim is to identify the thermal inertia of the assembly in real façades, based on numerical models validated by experiments under controlled conditions. The consideration of different enclosures with different thermal mass directly affects the inertia of 
the whole system. Furthermore, the comparative modeling of these different closure solutions is of great interest to determine the final thermal behavior of the façade [4].

The thermal inertia of two different façades (the so called traditional versus then ventilated façade) is studied. In this sense, the ventilated facade is the one with higher numerical behavior ignorance. Ventilated façades are based on an inner sheet comprising a supporting brick, concrete block or ceramic block with an external insulation. The cladding ventilated sheet is anchored on this. Nevertheless, this technology has two weak points: on the one side the limited possibilities of industrialization; on the other side, the possible thermal bridges creation in the grid profiles anchors. Complementary, the final resolution techniques involves the inclusion of an interior cladding based plasterboard in order to reduce the chases on the carrier sheet.

In recent years, with the intention of solving these weak points, the building industry offers alternatives, lighter than the traditional section. These adaptations will be applied for outdoor use of multi-layer plasterboard. In this sense, actually two ventilated façade are installed: light and heavy ventilated façade.

The present work has a double objective: the comparison between different insulation thickness and the analysis of modulation in thermal behavior of a ventilated façade beyond regulatory standards.

On the one hand the comparison between the evaluation of the influence of the insulation thickness in the thermal behavior is considered. The dynamic thermal behavior of a lightweight enclosure is compared to a conventional enclosure, adjusted to strict compliance with Spanish legislation for energy savings. Three levels for lightweight enclosure solutions are analyzed. The first one corresponds to the strict compliance with the Spanish legislation, the second one corresponds to optimum insulation values for the climate zone of Valencia (Spain) extracted from the study: U-values for better energy performance of buildings [5]; and the last one corresponds the recommended values for vertical enclosures in the certification [6].

On the other hand, the second objective of this research intends to evaluate whether decreasing the transmittance of the enclosure, beyond the standards of the Spanish regulations [7], modulates the behavior of a ventilated façade in terms of different daily, seasonal or local radiation loads.

One of the most interesting contributions of this work is the numerical model of different multilayer façades. The numerical model has been validated with experimental data, becoming then a powerful tool to predict other sort of similar façades, including ventilated air flow chamber. Thermal building models allow for the systematic formulation and solution of reasonably complex systems since any façade can be modeled by a system of first-order differential equations ([8], [9], [10], [11], [12], [13]). Such models have been used extensively for the dynamic modeling of buildings under the influence of outdoor conditions and changing building parameters; included multilayer façades ([14], [15], [16], [17], [18]).

\section{METHODOLOGY: BUILDING SYSTEMS AND TESTING METHODS.}


This paper presents a numerical model of heat transfer through two types of enclosures commonly used in contemporary construction, conventional façade so called "Façade 1 " and the light ventilated façade so called "Façade 2". Numerical results are compared with experimental measurements of temperature along the enclosure, in the environmental conditions of Valencia, Spain. Valencia has a subtropical climate on the borderline of the Mediterranean climate, with very mild winters and long warm to hot summers, according to Köppen climate classification [19].

In order to perform the experimental measurements under controlled conditions, the façades under study have being incorporated on a prototype. Temperatures will be measured in different points of the façades. Then, the modeled temperatures have been compared with those expected by applying ISO 13786:2007 [20].

It should be noted that the Facade 2 features a ventilated air space, changing the dynamics of heat transfer from the enclosure. Considering regulatory effects, the ventilated chamber represents no effect on the calculation of the thermal inertia of the facade, and therefore it is not considered. However, the proposed modeling shows that, in fact, the effect of air movement itself affects heat transmission. Furthermore, a numerical model is proposed to quantify this effect.

\subsection{Façade systems considered in this study.}

Four different façades are analyzed in the present study. On the one hand, Façades 1 and 2 are compared as a conventional and ventilated systems. On the other hand, Façades 3 and 4 are both ventilated, but a layer of rock wool is added, with different thickness.

The Façade 1 (conventional), with a total thickness of $235 \mathrm{~mm}$, is conceived with a constructive design strictly conformed to compliance energy saving Spanish CTE DB HE 1 [7].

Its section is composed of the following materials and elements from outside to inside (Figure 1).

A - Layer of cement mortar rendering, $10 \mathrm{~mm}$ thick.

B - Sheet of ceramic bricks triple hollow, $115 \mathrm{~mm}$ thick.

C - Layer of thermal insulation consists of extruded polystyrene, $30 \mathrm{~mm}$ thick and $30 \mathrm{~kg} / \mathrm{m}^{3}$ density.

D - No ventilated air chamber, $10 \mathrm{~mm}$ thick.

$\mathrm{E}$ - Sheet of double hollow ceramic brick, $70 \mathrm{~mm}$ thick.

The Façade 2 (light ventilated), with a total thickness of $280 \mathrm{~mm}$, is designed with a constructive section with the following materials and elements, from outside to inside (Figure 2):

F - Exterior ceramic coating of $15 \mathrm{~mm}$ thick, named Bionictile $\complement$, by Ceracasa [21].

$\mathrm{G}$ - Ventilated air chamber, $110 \mathrm{~mm}$ thick

$\mathrm{H}$ - Prefabricated sandwich panels. This section is designed with two steel sheets of $0,6 \mathrm{~mm}$ thick, between which there is a layer of rock wool of $100 \mathrm{~mm}$ thick and $70 \mathrm{~kg} / \mathrm{m}^{3}$ density, as a thermal insulation. 
I - No ventilated air chamber, $40 \mathrm{~mm}$ thick.

J- Simple plasterboard of $15 \mathrm{~mm}$ thick, bolted to its own subframe, with channels and uprights made of galvanized steel sheet of $0,6 \mathrm{~mm}$ thick. Total thickness of $46 \mathrm{~mm}$.

\subsection{Parameters used for the thermal inertia consideration across the wall}

In order to characterize the dynamic thermal properties of an enclosure, the standard ISO 13786:2007 can be used.

The principle behind this rule is to calculate by means of Fourier Equation (2) the heat transfer in closures formed by cladding in flat, parallel, solid, and homogeneous layers, under harmonic boundary conditions [22] along a relevant time period.

Thus, if we fix temperatures $(T)$ or heat intensities $(q)$ in the external and/or internal surfaces and put harmonic conditions on the other surface, we obtain steady state harmonic responses. These results are presented in the so called transfer complex matrix. In this particular research, the relevant parameter is the periodic thermal transmittance $Y_{12}$ defined as:

$$
Y_{12}=\left.\frac{q_{2}}{T_{1}}\right|_{T_{2}=0}
$$

The modulus in Eq. (1) quantifies the enclosure efficiency from the isolating point of view. INJ addition, the argument of (1) represents the lag that occurs between the outer and inner environments.

\subsection{Experimental prototype}

In order to model both façades, a real test under real weather conditions has been developed. The purpose of these tests is to validate the theoretical models; and furthermore to vary the climatic conditions for evaluating their dynamic behavior.

The two enclosures previously defined are tested. The first one with the façade (Figure 1) and the second pattern with the facade 2 (Figure 2). The test consists of two twin blocks in which the enclosure exposed to south runs the constructive solution to be tested (Figure 3). Once stabilized, interior temperatures are maintained at a constant temperature by an air conditioning system. Temperatures are recorded in each layer placed in the enclosures through the positions described in Figures 1 and 2.

\section{THE NUMERICAL MODEL}

In order to calculate the thermal behavior of a multilayer enclosure, both phases: solid and fluid, must be distinguished. In the solid phase, in absence of external heat sources, the temperature distribution is provided by the Fourier equation

$$
\nabla(k \nabla T)=\rho c_{p} \frac{\partial T}{\partial t}
$$


Where $(\rho)$ represents density, $(k)$ the conductivity and $\left(c_{p}\right)$ the specific heat. However, in the fluid phase, all the factors of heat transmission must be considered. Apart from conduction, the mass transfer must be added to the previous equation ( $\vec{u}$ is the fluid velocity).

$$
\nabla(k \nabla T)=\rho c_{p}\left(\frac{\partial T}{\partial t}+\vec{u} \cdot \nabla \mathrm{T}\right)
$$

The fluid movement is described by Navier-Stokes Equation

$$
\rho \frac{\partial \vec{u}}{\partial t}-\nabla\left(\eta\left(\nabla \vec{u}+(\vec{u})^{T}\right)\right)+\rho(\vec{u} \cdot \nabla) \vec{u}+\nabla p=\vec{f}
$$

And continuity equation

$$
\frac{\partial \rho}{\partial t}+\nabla \cdot(\rho \vec{u})=0
$$

Where $(\eta)$ is the kinematic viscosity and $(\vec{f})$ gravity by volume unit in this case. The radiation in the solid layers in contact with the fluid (when this fluid does not participate) is described by the Stefan-Boltzmann equation

$$
E=\epsilon \sigma T^{4}
$$

where $(E)$ is the total emissive power, $(\epsilon)$ the surface emissivity and $(T)$ the absolute temperature in the surface, considered isothermal, and $\sigma$ the Stefan-Boltzmann constant.

The complete solution of the problem considers the equation (2) in the solid layers of enclosure along with the coupled (3-4-5) in the fluid. This will be done by considering that the boundary conditions are the continuity of heat intensity $(-k \nabla T)$ between solid layers and the jump caused by radiation in solid-fluid interfaces (inner surfaces and external and internal surfaces). While equation (2) is easily solvable by numerical methods, equations (3), (4) and (5) form a system of coupled elliptic differential equations highly nonlinear and explosive. Therefore some simplifications are mandatory.

These simplifications are mainly two: On the one side the fluid (air) is considered incompressible except for the buoyancy effect due to differences in density (Boussinesq approximation, [23], On the other side both density and viscosity are taken as constants, this is in fact true in the small variation temperature range modeling of this problem $(<4 K)$. The equations (3),(4) and (5) become:

$$
\begin{gathered}
\alpha \Delta \mathrm{T}=\frac{\partial T}{\partial t}+\vec{u} \cdot \nabla \mathrm{T} \\
\rho_{0}\left(\frac{\partial \vec{u}}{\partial t}+(\vec{u} \cdot \nabla) \vec{u}\right)-\eta \Delta \vec{u}+\nabla p=-\alpha \rho_{0} \vec{g}\left(T-T_{0}\right) \\
\nabla \vec{u}=0
\end{gathered}
$$

Where $\left(\alpha=\frac{k}{\rho c_{p}}\right)$ is the thermal diffusivity and $\left(\rho_{0}\right)$ the density of the fluid medium at the average temperature $\left(T_{0}\right)$ 
To incorporate the effect of radiation in the air chambers, the form factor is considered as unity. This is possible given the relationship between the thickness of these with transverse dimensions. Thus, the radiation pattern appears in the model as a discontinuity $(\delta q)$ in heat intensity value between surfaces $(i-j)$ with the value

$$
\delta q=\varepsilon_{c} \sigma\left(T_{i}^{4}-T_{j}^{4}\right)
$$

Where $\left(\varepsilon_{c}^{-1}=\varepsilon_{i}^{-1}+\varepsilon_{j}^{-1}\right)$ is the joint emissivity and $\left(T_{i}\right)$ and $\left(\varepsilon_{i}\right)$ the temperature and emissivity of the layer i.

Some more simplifications can be done in the model to reduce the computational effort with little impact on the accuracy of the results.

First, the problem of heat transfer between the interior and exterior environments with closure elements can be avoided. To this end, the boundary conditions for the external and internal layers will be imposed rather than the ones for the environments. This greatly simplifies the problem of external foil directly exposed to solar radiation varying with time and weather conditions.

Furthermore, the transferring heat in a sealed air chamber is a well established phenomenon and perfectly quantifiable. Thus, the effect can be considered as a sealed air layer with a thermal resistance given by ISO-6946:1996 [24].

The model represents a series of solid layers characterized by their density, conductivity and specific heat, governed by equation (2) together with an open air chamber described by equations $\left(3^{\prime}\right)\left(4^{\prime}\right)\left(5^{\prime}\right)$. The boundary conditions are the following: between the solid layers we assume continuity of the heat flux whereas at the solid fluid interfaces we assume the discontinuity of the heat flux done by the equation $\left(6^{\prime}\right)$ and no-slip at the wall.

The boundary conditions on the external layers consist on presetting temperatures in the outer and inner sheets of the time-varying envelope together with the outside air temperature at the bottom of the air layer.

Since the depth of the enclosure is substantially larger than the thickness of the enclosure, that dimension can be eliminated of the model, neglecting edge effects and significantly reducing the computation time.

The computations were performed in a Finite Element Analysis commercial package, COMSOL Multiphysics v 3.5 running in a cluster of 4 Intel Xeon CPU's (24 processing Cores) with 86 GB of memory. Some calculations took several days in this machine.

\subsection{Results of the numerical model: validation.}

Applying the model to the Façade 1, over a period of 24 hours for a sunny winter day, the temperature distribution for the control points (Tp1-Tp6) is obtained. In figure 4, the comparison between numerical (down) and experimental (top) values of temperatures are presented. 
The same results, modeled for Façade 2, in the enclosure distribution (Tp1-Tp6), are represented in Figure 5: numerical (down) and experimental (top) values.

The temperatures in three points inside the ventilated air layer (low, med and high) are represented, together with the temperatures in the two air chamber foils ( $p 2$ and p3) and the external air, in Figure 6, numerical (down) and experimental (top) values.

As it can be observed in both figures, in all cases, there is a good agreement between the experimental values and those obtained with the model.

A final value is obtained for the periodic thermal transmittance $\left|Y_{12}\right|$ of $0.56 \mathrm{~W} / \mathrm{m}^{2} \mathrm{~K}$ with a gap of -4.45 hours. This has been achieved considering harmonic variations with a period of 24 hours in the external face and a constant temperature in the conventional internal enclosure. The same calculation done by means of the ISO 13786:2007 [20] gives values of $0.54 \mathrm{~W} / \mathrm{m}^{2} \mathrm{~K}$ for the periodic thermal transmittance with a -4.42 hours gap.

Two different procedures can be used in the Façade 2 model. On the one side the air in the ventilated chamber can be considered with a constant temperature: the external mean temperature; on the one side, the air temperature can be changed as the external conditions do.

In the first assumption, the temperature will be considered constant and equals to $0{ }^{\circ} \mathrm{C}$, getting for the thermal periodic transmittance $\left|Y_{12}\right| 0.185 \mathrm{~W} / \mathrm{m}^{2} \mathrm{~K}$ and a gap of -1.97 hours. In the second assumption the gap is the same, but $\left|Y_{12}\right|$ becomes $0.266 \mathrm{~W} / \mathrm{m}^{2} \mathrm{~K}$.

Furthermore, the calculation method presented in ISO 13786:2007 [20], considering the air layer as sealed, $\left|Y_{12}\right|$ gives a value of $0.26 \mathrm{~W} / \mathrm{m}^{2} \mathrm{~K}$ with a gap of -1.93 hours.

In this case, the temporal gap predicted by the ISO [20] and the experimental value for temporal gap coincide, but the periodic thermal transmittance $\left|Y_{12}\right|$ only coincide in both estimations, if the exterior air temperature changes as the exterior conditions do. Opposite, there is a significant discrepancy in this value if the air temperature is fixed with a medium value. This is graphically presented in Figure 7.

\subsection{Modeling other façades: determination of inertia in ventilated façade.}

Once validated the model, the effect on the thermal inertia of the air is analyzed, reducing the total transmittance enclosure. Accordingly, from the Façade 2 (light ventilated) described above (see Figure 2), now two new light ventilated façades are modeled. These new façades are built replacing the layer $I$ of the Façade 2 by a new layer, named $l$ ', with two different thicknesses of thermal insulation (Figure 8).

Façade 3 has a total thickness of $280 \mathrm{~mm}$. In this case, the layer I' has rock wool as a thermal insulation, with $40 \mathrm{~mm}$ thickness and $70 \mathrm{~kg} / \mathrm{m}^{3}$ density. This is the isolation level defined in the study U-values for better energy performance of buildings [5]. In the case of Façade 4, with a total thickness of $380 \mathrm{~mm}$, the layer I' has the same thermal insulation, with $140 \mathrm{~mm}$ thickness. Now, with this isolation level, the Passive House certification could be reached [6]. 
When the temperature in the air chamber is considered constant, the numerical model applied to Façades 3 and 4 provides the next values: In Façade $3\left|Y_{12}\right|=0.1365 \mathrm{~W} / \mathrm{m}^{2} \mathrm{~K}$ and time lag of $-3.00 \mathrm{~h}$. In Façade $4\left|Y_{12}\right|=0063 \mathrm{~W} / \mathrm{m}^{2} \mathrm{~K}$ and time lag of -6.00 hours in Façade 4 . These same calculations, using ISO [20] provide for Façade 3 the values of $\left|Y_{12}\right|=0.193 \mathrm{~W} / \mathrm{m}^{2} \mathrm{~K}$ and time lag of -3.02 hours; and $\left|Y_{12}\right|=0.083 \mathrm{~W} / \mathrm{m}^{2} \mathrm{~K}$ and a time gap -6.01 hours for Façade 4 .

In both cases, a perfect agreement between the two methods in the calculation for the time gap is achieved. However, the model yields values of the order of $25 \%$ lower for the module of periodic thermal transmittance when the temperature air chamber is considered constant. These results are summarized in Table 1.

\section{Discussion}

Comparing the values provided by the model with the experimental results (from Figures 4, 5 and 6) it can be concluded that the temperature distribution in the enclosure is well approximated by the model in both sort of façades. This validation aims the modelers to use it for other circumstances; in more complex and/or more costly commissioning on site.

Derived from this analysis of the results, it is observed than the increase in the use of thermal isolation affects both the thermal periodic transmittance and the time lag. The effect on the time lag is compensated even when the mass of the façade clearly decreases.

Analyzing table 1, two aspects are derived: On the one hand, the concordance model with ISO 13786:2007 is excellent in the conditions of applicability of the standard, i.e. for solid partitions and/or watertight air chambers (or when it is treated as fully ventilated in accordance with ISO6946: 1996). On the other hand the model provides significantly lower values for the modulus of the periodic thermal transmittance (nearly $30 \%$ ) when the air temperature in the chamber is kept constant.

The important question is if this assumption (keeping the temperature of the air in the chamber stationary) is a realistic representation for the physics of the problem. Figure 9 represents the experimental average temperature of the air in the air chamber $\left(T_{\text {avg air }}\right)$ and the temperature of the external foil layer (the side directly exposed to the external solar radiation (Tp1)) versus time.

It is observed that the difference between the average air temperature in the chamber and the outside foil of the enclosure changes in a different way depending on the existence of radiation on the external side. The temperature follows variations of the outer layer when no direct sunlight impinges on it, with a slight $7 \%$ difference between the two layers temperature. However, with direct solar radiation on the enclosure, the air in the chamber has certain inertia, and the difference of temperatures gets clearly increased, up to $30 \%$.

In the same Figure 9, the relative difference, between the temperature of the external foil exposed directly to the sun and the average temperature of the air in the chamber is shown.

$\left(\Delta T_{\text {rel air }}=100 \cdot \mid \frac{T p_{1}-T_{\text {avg air }}}{T p_{1}}\right)$. It can be seen that this relative difference of temperatures is considerably higher when the sun shines directly on the outer sheet. When there is not solar radiation incident on the façade, the air chamber behaves as the ISO [20] indicates: following 
the external temperature variation, with no effect of air movement inside the chamber. However, when the effect of radiation is considered, the difference of temperatures between interior and exterior layers highly increases. Nevertheless, this increase is smaller than if the air had no movement, decreasing $\left|Y_{12}\right|$. In this case, when the solar radiation incise on the façade, is when the ventilated façade more decreases the inside temperature.

\section{Conclusions}

In the present paper, a model for the thermal transmittance along different façades has been described. This model has been validated using two different sort of façades: one considered as "traditional" and lighter one considered "ventilated" with an open air layer. According to a 24 hours experiment, the temperature of the different layers of the façades has been measured. At the same time, a thermal model of the heat transfer and fluid dynamics of the layers present in the façades has been developed in order to represent the temperature variation in each of them.

The numerical model has been validated for these two initial façades, and it has been used for representing the behavior of two new different façades using different isolations. From the analysis of the results it has been considered that for the different façades, the effect on the time lag is compensated even when the mass of the façade clearly decreases.

Besides, the behavior of temperatures in the air chamber of the ventilated façade has been deeply analyzed to quantify the changes occurred along the day. When there is no solar radiation, the air follows the external temperature variation, with almost no effect of air movement inside the chamber. However, when the effect of radiation is considered, the difference of temperatures between interior and exterior layers highly increases, and in this moment is when the ventilated façade more decreases the inside temperature, almost $30 \%$.

In this case, this is a quantification of the effect of the presence of the air layer in the façade. In warm climates this effect is important for the cooling necessities, and it will suppose an important decrease of the energy needed for maintaining comfort inside the buildings. The quantification with a validated model of the thermal effect of the façade, gives the modelers an accurate tool for analyzing the effect of the façade in thermal transmittance in different external conditions and puts in evidence that there is no necessity of increasing the mass for increasing the transmittance.

\section{Acknowledgements}

The evaluation of the different of the façade systems, by modifying the multilayer sandwich panels has been performed in the framework of the E3 EDIFICACIÓN ECO EFICIENTE project. The research project is cofounded by CDTI and a consortium of companies formed by BECSA, CERACASA, Rockwool Peninsular, ATERSA and APLICAD. 
The tests have been performed in Instituto Tecnológico de la Construcción AIDICO (Valencia, Spain) at the laboratory eeLAB, under the supervision of Alejandro García and Diana Mora.

\section{REFERENCES}

[1]. Aste, N.; Angelotti, A., Buzzetti, M. 2009. The influence of the external walls thermal inertia on the energy performance of well insulated buildings. Energy and Buildings 41 (2009) 1181-1187.

[2]. Y. Feng, Thermal design standards for energy efficiency of residential buildings in hot summer/cold winter zones, Energy and Buildings 36 (2004) 1309-1312.

[3]. D. Saelens, J. Carmeliet, H. Hens, Energy performance assessment of multiple skin facades, HVAC\&R Research .9 (2) (2003) 167-186.

[4]. K. Gregory, B. Moghtaderi, H. Sugo, A. Page, Effect of thermal mass on the thermal performance of various Australian residential construction systems, Energy and Buildings 40 (2008) 459-465.

[5]. EURIMA ECOFYS. Boermans, T; Petersdorff. U-values for better energy performance of Buildings. 2005.

[6]. Passive House Institute. http://passiv.de/en/02_informations/02_passive-house-requirements/02 _passive-house-requirements.htm. Consulted online on November 2013

[7]. CTE DB HE 1. Codigo Técnico de la Edificación. Documento Basico. Ahorro de Energia. Consultado en http://www.codigotecnico.org/web/recursos/documentos/. Consulted online on November 2013.

[8]. Haase, M. ; Marques da Silva, F. ; Amato, A. 2009. Simulation of ventilated facades in hot and humid climates, Energy and Buildings, Volume 41, Issue 4, April 2009, Pages 361-373, ISSN 0378-7788, http://dx.doi.org/10.1016/j.enbuild.2008.11.008.

[9]. De Gracia, A. Castell, A. Navarro, L., Oró,E., Cabeza, L.F. 2013. Numerical modelling of ventilated facades: A review, Renewable and Sustainable Energy Reviews, Volume 22, June 2013, Pages 539549, ISSN 1364-0321, http://dx.doi.org/10.1016/j.rser.2013.02.029.

[10]. Seunghwan Y., Hakgeun J., Byung-Lip A., Hyesim H., Donghyun S., Junghoon L., Cheol-Yong J. 2013. Thermal transmittance of window systems and effects on building heating energy use and energy efficiency ratings in South Korea, Energy and Buildings, Volume 67, December 2013, Pages 236244, ISSN 0378-7788, http://dx.doi.org/10.1016/j.enbuild.2013.08.005.

[11]. Fuliotto, R.; Cambuli, F.; Mandas, N.; Bacchin, N.; Manara, ; Chen, Q. 2010. Experimental and numerical analysis of heat transfer and airflow on an interactive building facade. Energy and Buildings 42 (2010) 23-28.

[12]. Saelens, D. , Blocken, B., Roels,S. and Hens, H. 2005. Optimization Of The Energy Performance Of Multiple-Skin Facades. Buiding Simulation 2005. Montreal. Canada.

[13]. Eicker, U; Fux, V.; Bauer, U; Mei, L.; Infield, D. 2008. Façades and summer performance of buildings. Energy and Buildings 40 (2008) 600-611.

[14]. Kontoleon, K. J. 2012. Dynamic thermal circuit modeling with distribution of internal solar radiation on varying façade orientations. Energy and Buildings 47 (2012) 139-150 
[15]. D. Beggas, A.J. Wilson, J. Zighiche, Simulation analysis of passive solar building based on the thermal network methods, Journal of Engineering and Applied Sciences 2 (2007) 1613-1619.

[16]. Balaras, C.A. 1996. The role of thermal mass on the cooling load of buildings: an overview of computational methods, Energy and Buildings 24 (1996) 1-10.

[17]. Kuznik, F.; Catalina, T.; Gauzere, L.; Woloszyn, M.; Roux, J.J. 2011. Numerical modelling of combined heat transfers in a double skin façade. Full-scale laboratory experiment validation. Applied Thermal Engineering 31 (2011) 3043-3054.

[18]. Zanghirella, F., Perino, M., Serra, V. 2011. A numerical model to evaluate the thermal behaviour of active transparent façades. Energy and Buildings 43 (2011) 1123-1138

[19]. M. Kottek; J. Grieser, C. Beck, B. Rudolf, and F. Rubel. 2006. "World Map of the Köppen-Geiger climate classification updated". Meteorol. Z. 15 (3): 259-263. doi:10.1127/09412948/2006/0130. Retrieved 22 April 2009.

[20]. ISO 13786:2007. (Thermal performance of buildings components. Dynamic thermal characteristics. Calculations methods).

[22]. Ceracasa. Bionictile. http://www.ceracasa.com/620800_en/BIONICTILE\%C2\%AE/. Consulted online on November 2013.

[22]. Carslaw and Jaeger. 1986 Conduction of Heat in Solids, Oxford University Press. Oxford. UK.

[23]. Incropera, F.P. 2011. Fundamentals of Heat and Mass Transfer, 4th ed. Prentice Hall. New Jersey. USA.

[24]. ISO-6946:1996. Building components and building elements -- Thermal resistance and thermal transmittance -- Calculation method 
Figure 1. Composition Enclosure 1: Façade 1

Figure 2. Composition Enclosure 2: Façade 2

Figure 3. Experimental setup. Detail of Façade 2

Figure 4. Distribution of temperatures in Façade 1. Experimental values on top, numerical down.

Figure 5. Distribution of temperatures in Façade 2. Experimental values on top, numerical down.

Figure 6. Distribution of temperatures in the interior of the chamber on Façade 2.

Experimental values on top, numerical down.

Figure 7. Temperature in the external foil layer (T1) and heat flux across the internal, in two conditions for the temperature in the air chamber: constant (q2_0) and following the external temperature (q2_var), in the Façade 2.

Figure 8. Composition Enclosure 3: Façade 3

Figure 9. Experimental average temperature of the air in the air chamber $\left(\mathrm{T}_{\mathrm{avg}}\right.$ air $)$ and the temperature of the external foil layer (Tp2) vs. time. Also the relative difference in percentage is represented ( $\Delta$ rel air). 


\begin{tabular}{|c|c|c||c|c|}
\cline { 2 - 5 } \multicolumn{1}{c|}{} & \multicolumn{2}{c||}{ Numerical } & \multicolumn{2}{c|}{ ISO 13786:2007 } \\
\cline { 2 - 5 } & $\begin{array}{c}\left|Y_{12}\right| \\
\left(W / \mathrm{m}^{2} \mathrm{~K}\right)\end{array}$ & $\begin{array}{c}\text { Time lag } \\
\text { (hours })\end{array}$ & $\begin{array}{c}\left|Y_{12}\right| \\
\left(W / \mathrm{m}^{2} \mathrm{~K}\right)\end{array}$ & $\begin{array}{c}\text { Time lag } \\
\text { (hours })\end{array}$ \\
\hline Façade 1 & 0.56 & -4.45 & 0.54 & -4.42 \\
\hline Façade2* & 0.185 & -1.97 & 0.260 & -1.93 \\
\hline Façade2 & 0.266 & -1.97 & & -3.02 \\
\hline Façade 3 & 0.1365 & -3.00 & 0.193 & -6.01 \\
\hline Façade 4 & 0.063 & -6.00 & 0.083 & \\
\hline
\end{tabular}

Table 1. Periodic thermal transmittance. Facade $2^{*}$ are simulated assuming temperature in the air chamber follows external temperature; otherwise temperature are keep constant when applicable. 

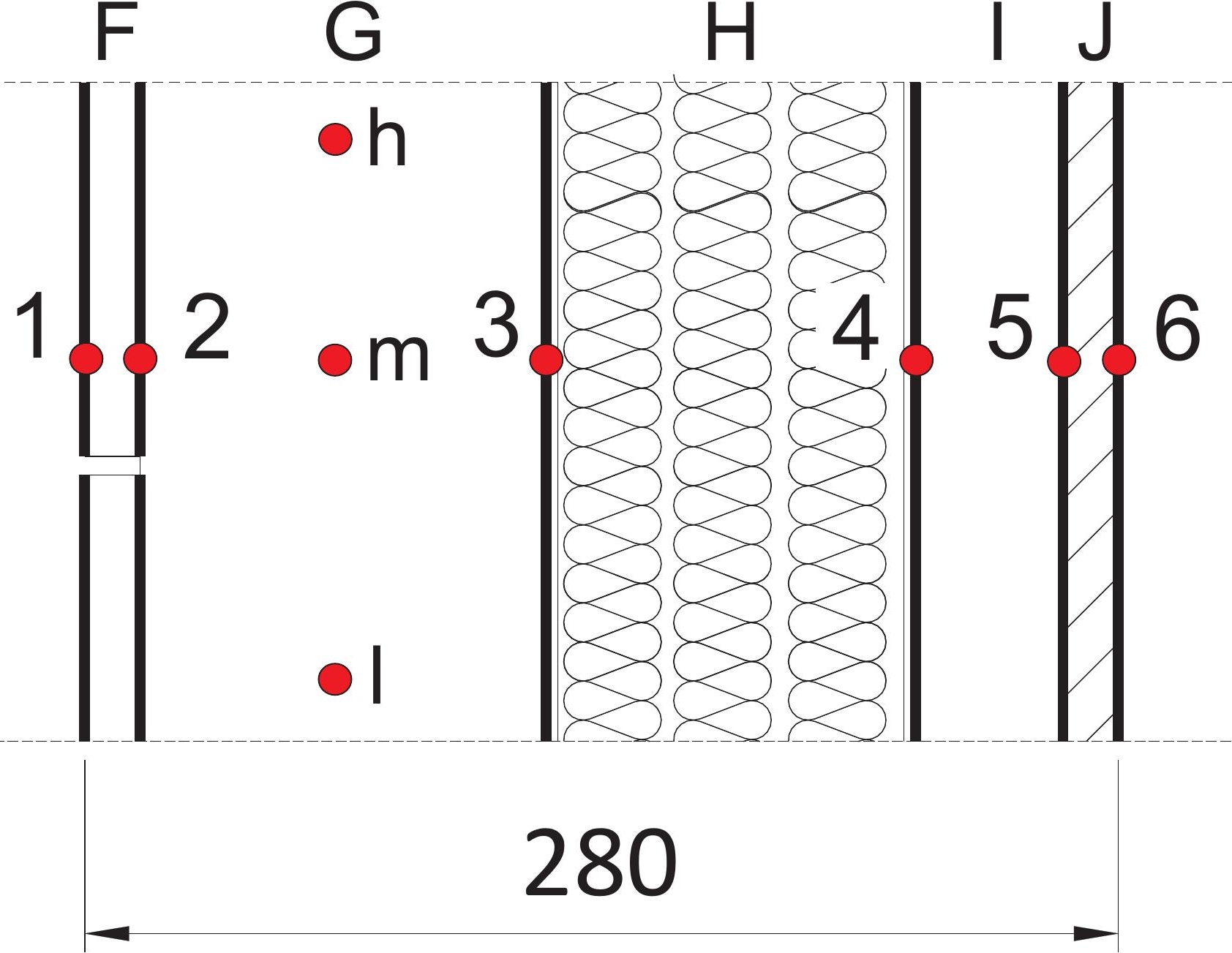


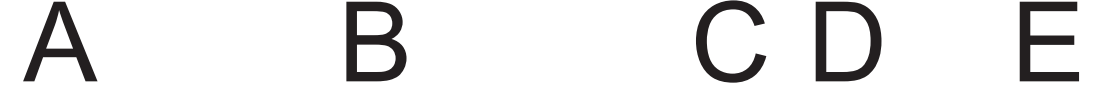

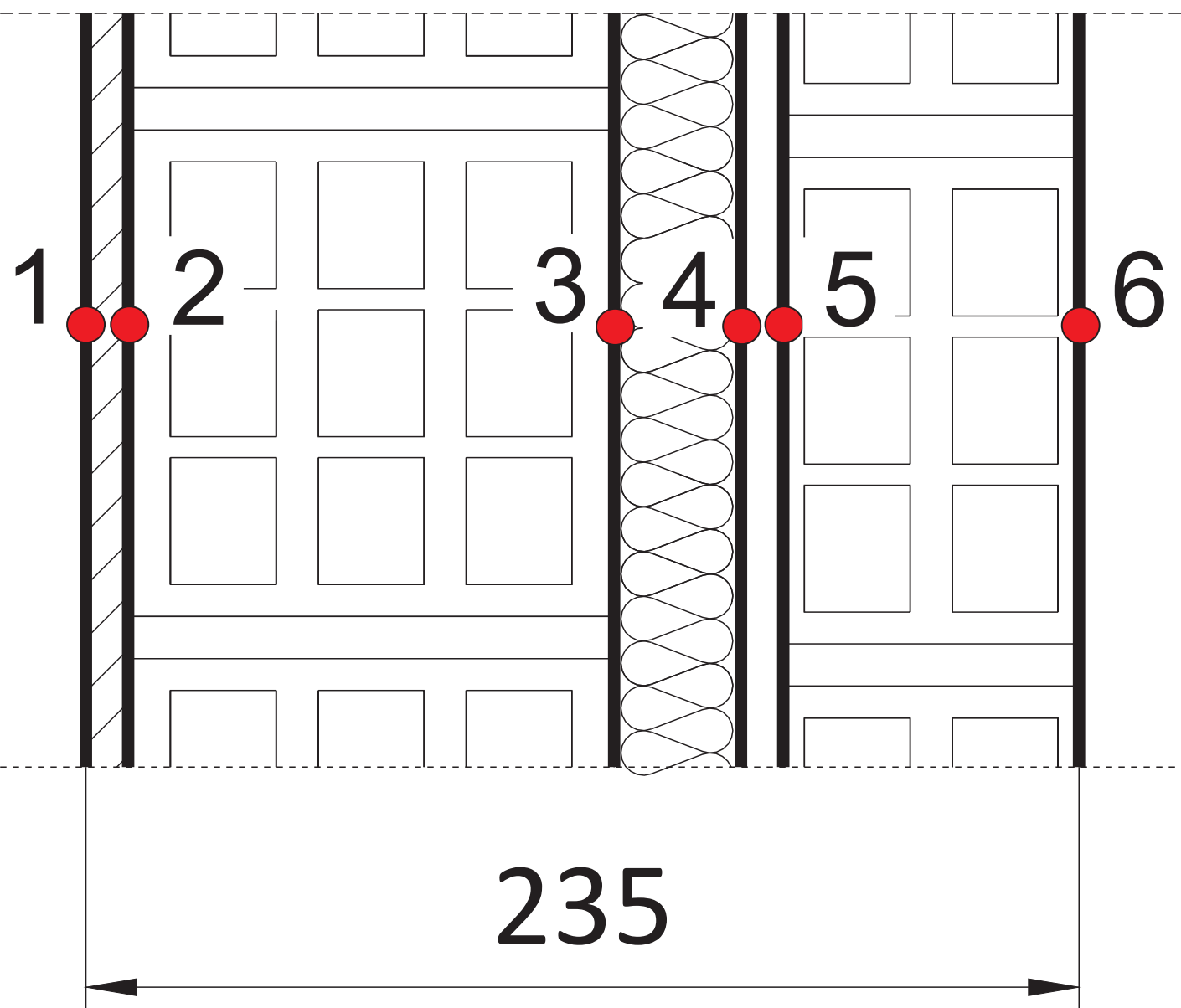




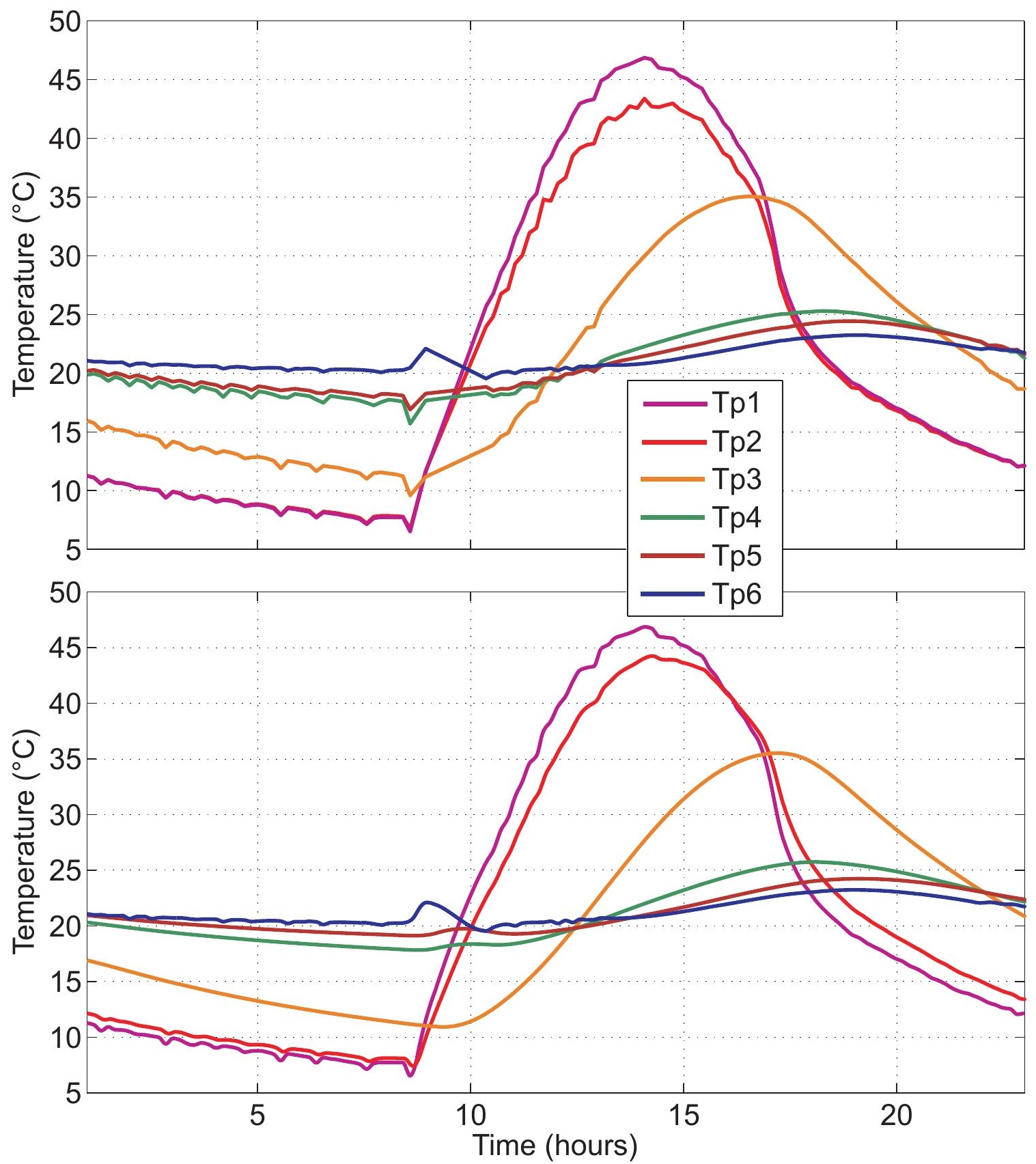




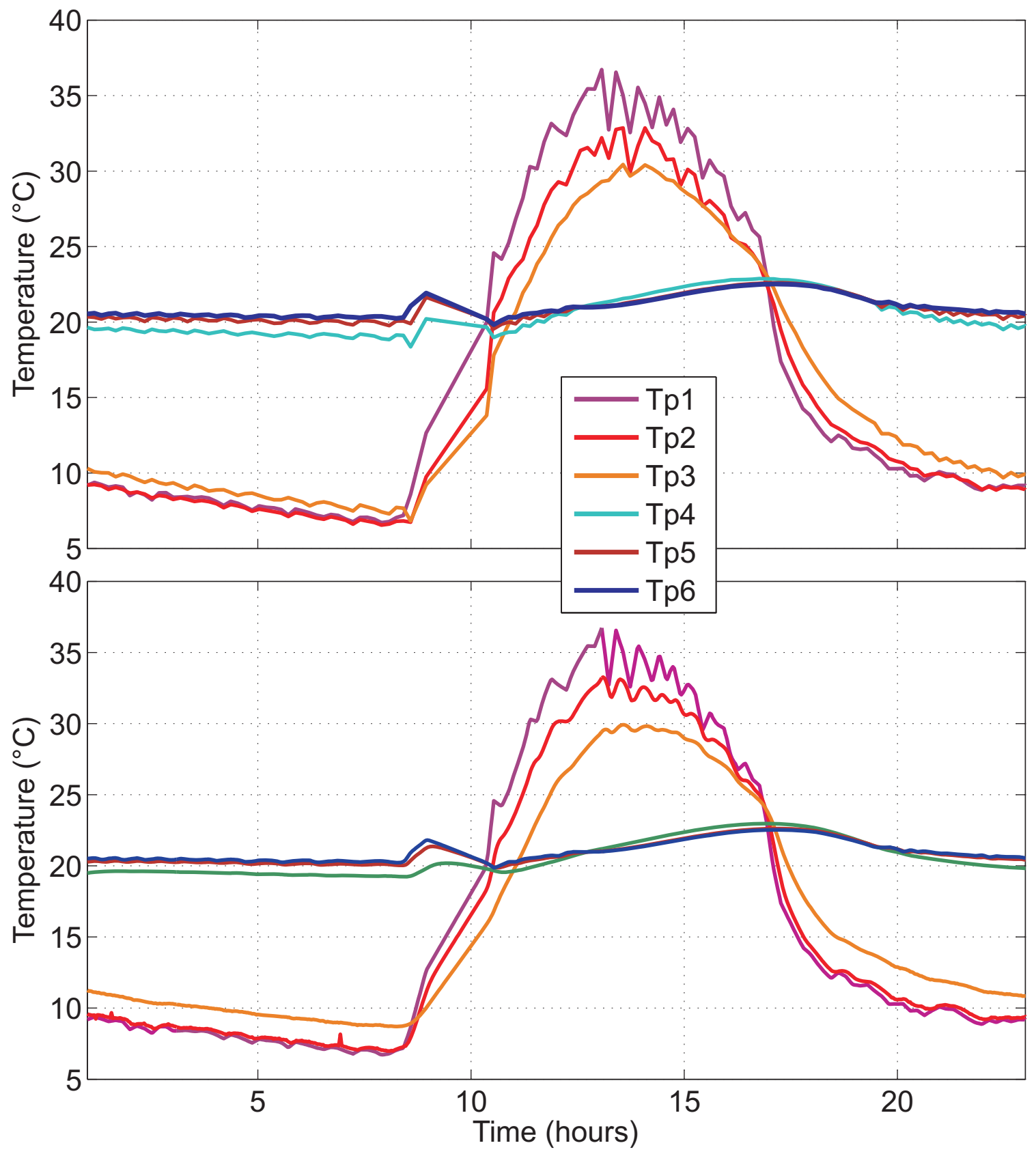




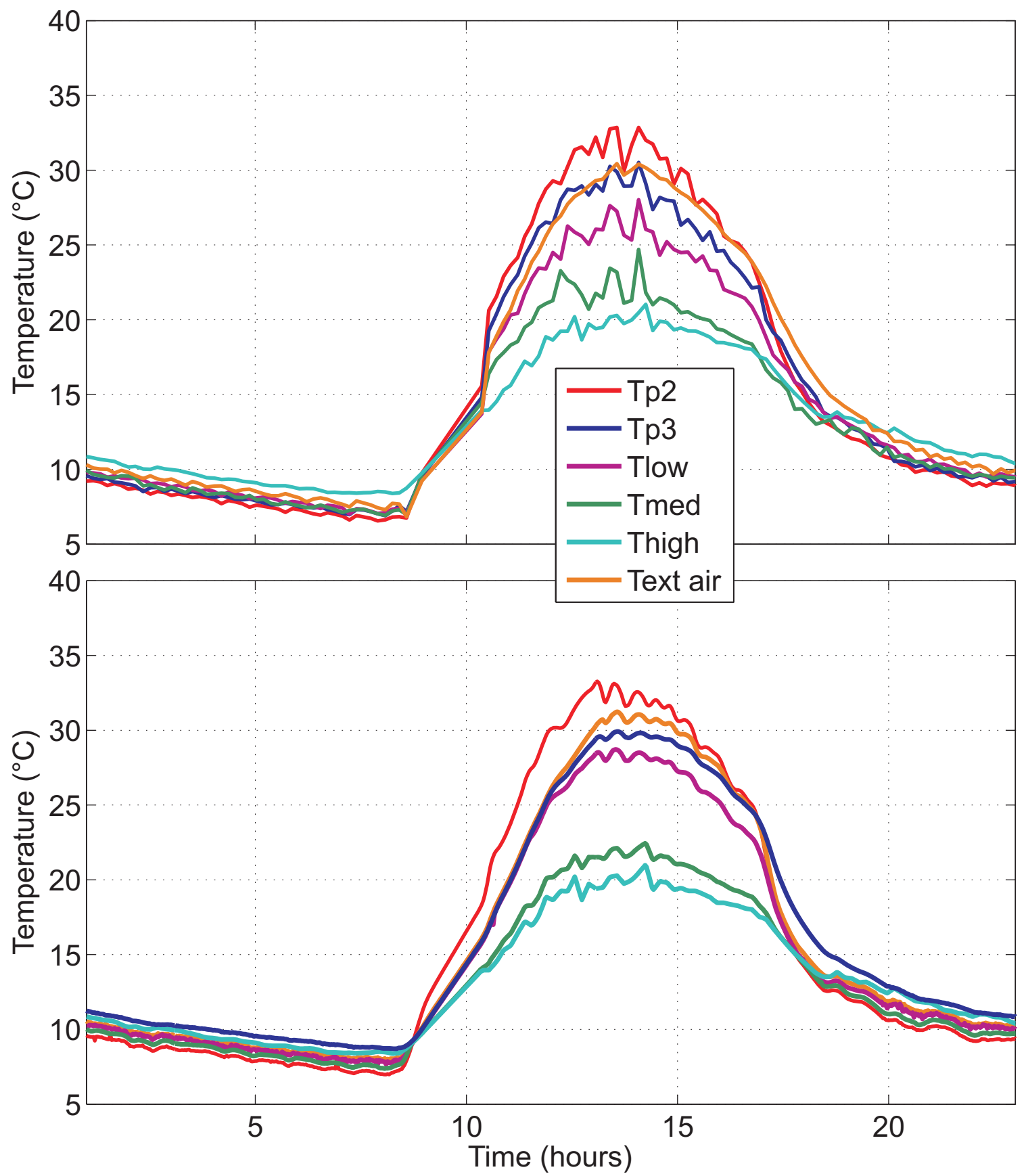




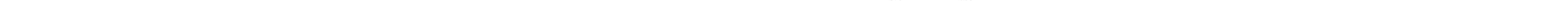




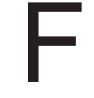

G $\quad H$

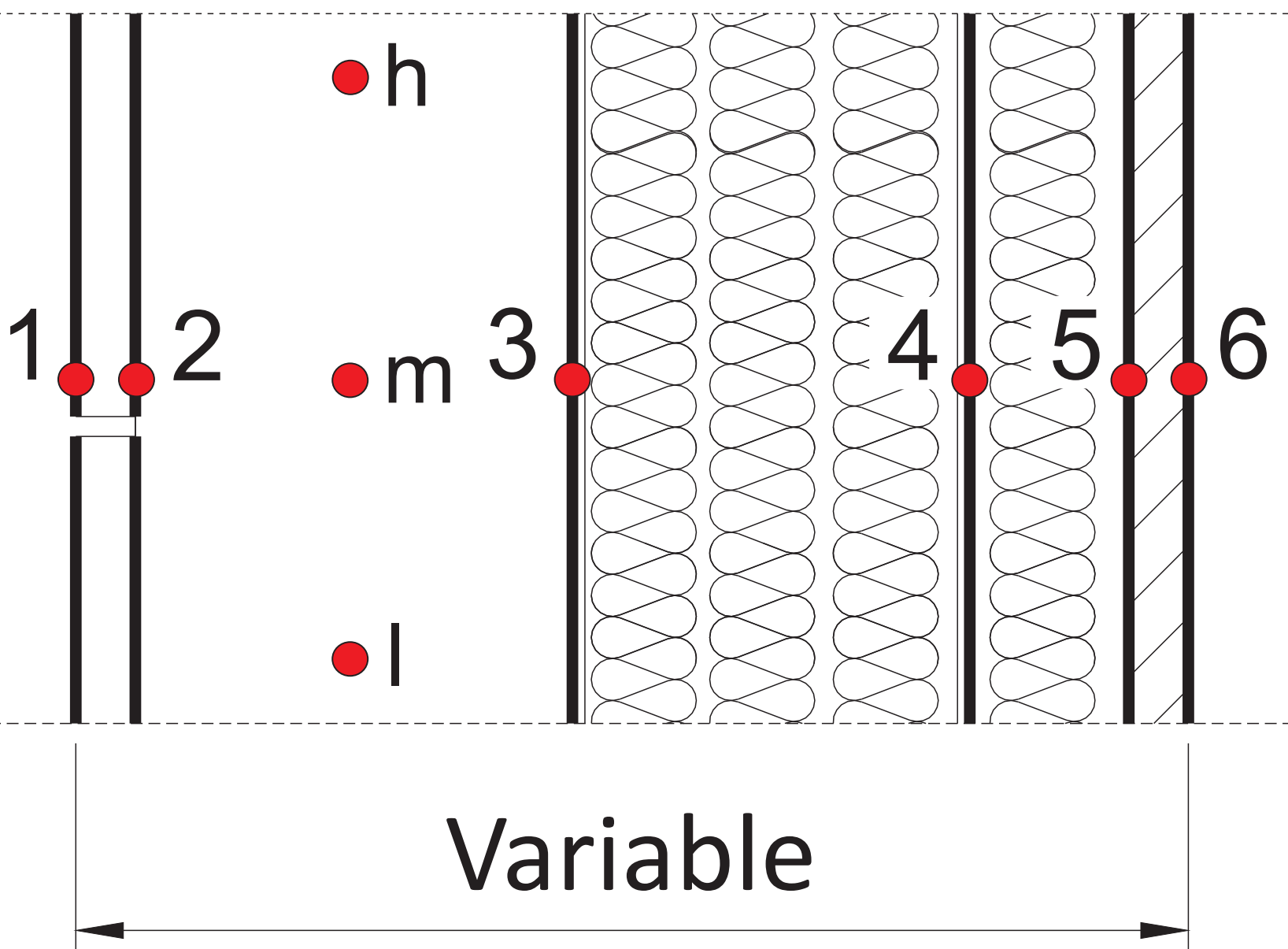




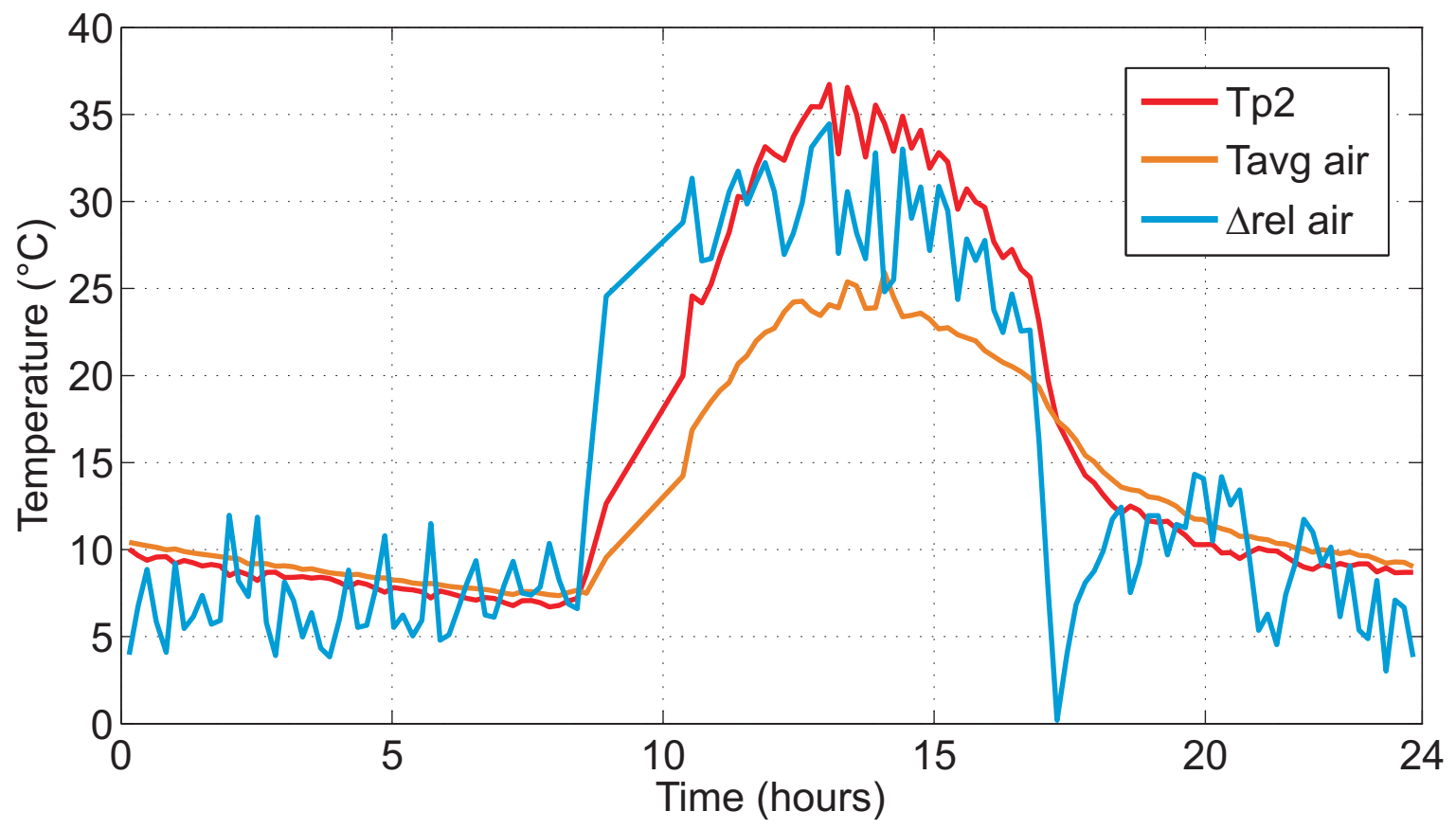

